\title{
Unmet contraceptive demand
}

In 2017, reports and information on maternal and neonatal mortality, induced abortions, unwanted pregnancies and family planning services estimated that half of the women living in developing countries avoid getting pregnant, but about $25 \%$ of them do not have access to modern contraceptive methods. ${ }^{1}$

The proportion of women with unmet contraceptive demand has been declining since 2014, although it has been declining even slowerwhen taking into an account the increase of women at reproductive age. 1

In developing countries, women with unmet need of contraception contribute with $84 \%$ of all unwanted pregnancies, either because they do not use any kind of methods $(74 \%)$ or because they use a traditional method $(10 \%)$. There are restricted access to family planning services, as well as limited supply of the methods, mainly faced by poor, young and unmarried women contributing to the restriction of modern, reversible and long-term use of contraceptive methods. In poor or developing countries this is a complex problem involving different aspects. Fear of the side effects or previous negative contraceptive experiences, Politician restrictions, cultural and religion are also barriers that may hinder pregnancy planning. No less important are the difficulties related to gender inequity as well as the individual characteristics and providers of professional expertise on family planning service. ${ }^{2}$

In addition to unplanned pregnancy, it has severe socioeconomic and environmental consequences. The disorganized population growth leads to shortages and unequal allocating resources, education and access to contraception, resulting in increased deaths of women at childbirth and unsafe abortions, abandoned children and impoverished families. 3

In Brazil, the percentage of unplanned pregnancies follows the tendency of developing countries, which remains above the world average. More than 55\% of the Brazilian women who had children in 2011 and 2012 did not plan their pregnancy,according to the data from the survey "Born in Brazil: a national survey on childbirth and birth," which 24,000 women wereinterviewed in 266 public hospitals in Brazil. In addition, more than 500 thousand unsafe abortions are performed every year in Brazil as a result of unwanted pregnancies. 3

On the other hand, a report from the United Nations in Brazil (ONUBR) 4 pointed out that $79 \%$ of the Brazilian women had some kind of contraceptive methods in 2015. Although, how can we explain that most Brazilian women use contraceptive methods, but more than half of the pregnancies that occur in Brazil are still unplanned?

The Brazilian Ministry of Health does not prioritize goals or strategies to reduce the number of unwanted pregnancies. There are no specific educational campaigns about family planning and contraception in this country, allowing the possibility of implementing ineffective family planning policies with unequal access to modern long-term contraceptive methods (copper IUD, of levonorgestrel and hormone implant), resulting in failure in providing these methods. To meet satisfactorily demand for reproductive planning through long-term modern methods will lead to a substantial impact on women's reproductive health reducing the incidence of unwanted pregnancies, induced abortions and consequently a reduction of maternal morbidity and mortality. Long-term contraceptive methods are safe and effective options for all kinds of women, and they have a high level of satisfaction, as well as a high rate of continuity use of the method, and a cost effective option. 5

Redesigning family planning policies to emphasis on reducing the barriers in having access to the health services, especially for sexual and reproductive health services, is a goal that needs to be strengthened in Brazil. 
To secure Brazilian women's unsatisfied sexual and reproductive health demands is feasible, if there are sociopolitical and economic commitment from local government health authorities, funding agencies, non-governmental organizations, families and citizens. ${ }^{6}$

Family planning is one of the most successful interventions in public health, since it provides good, sustainable family planning services with continued public health campaigns and are prominent in offering and having access to all contraceptive methods. It is also important to "demedicalize" the full range of contraceptive methods provided by trained and qualified "non-physicians", expanding the scope of contraceptive counseling and education in all women's reproductive stages including prenatal, postpartum and post-abortion always taking into account each couple's individual needs. By making an informed contraceptive choice with access to all types of contraceptive methods, especially long-lasting methods, women will have less chance of unwanted pregnancy and to endanger her own life. ${ }^{7}$

Incentives to family planning based on the couples' sexual and reproductive rights are some of the actions promoted by the World Health Organization (WHO) to strengthen family planning in the world. ${ }^{1}$

The Brazilian Journal of Maternal and Child Health welcomes and considers relevant researches on WHO's action strategies, evidence-based guidelines and operational technical support measurements. Thus, the Journal's editorial team supports the scientific community in research and data refinement production, allowing a better understanding on complex reasons that nowadays leads a woman at a reproductive age not to use contraceptive methods.

\section{References}

1. Adding it up: Investing in Contraception and Maternal and Newborn Health, 2017. Estimation Methodology, New York: Guttmacher Institute, 2018. [acesso em 4 de Out 2018]. Disponível em: https://www.guttmacher.org/sites/default/files/report_pdf/ adding-it-up-2017-estimation-methodology.pdf

2. Alkema L, Kantorova V, Menozzi C, Biddlecom A. National, regional and global rates and trends in contraceptive prevalence and unmet need for family planning between 1990 and 2015: a systematic and comprehensive analysis. The Lancet. 2013; 381 (9878): $1642-52$.

3. Diniz DM, Medeiros M, Madeiro A. Pesquisa Nacional de Aborto 2016. Ciênc Saúde Colet. 2017; 22 (2): 653-60.

4. ONUBR (Nações Unidas no Brasil). Cerca de 79\% das brasileiras usaram métodos contraceptivos em 2015, informa ONU. [acesso em 5 Nov 2018]. Disponível em: https://nacoesunidas.org/cerca-de-79-das-brasileiras-usaram-metodos-contraceptivos-em2015-informa-onu/

5. Braga GC, Vieira CS. Anticoncepcionais reversíveis de longa duração: Implante Liberador de Etonogestrel (Implanon). Femina. 2015; 43 (Suppl. 1): S7-14.

6. Leal MC, Silva AAM, Dias MAB, Gama SGN, Rattner D, Moreira ME, Filha MM, Domingues RM, Pereira AP, Torres JA, Bittencourt SD, D'orsi E, Cunha AJ, Leite AJ, Cavalcante RS, Lansky S, Diniz CS, Szwarcwald CL. Birth in Brazil: national survey into labour and birth. Reprod Health. 2012; 9 (15): 1-8.

7. O'neil-Callahan M, Peipert JF, Zhao Q, Madden T, Secura G. Twenty-four-month continuation of reversible contraception. Obstet Gynecol. 2013; 122 (5): 1083-91.

\section{Ana Laura Carneiro Gomes Ferreira 1 Ariani Impieri Souza 2}

1,2 Instituto de Medicina Integral Prof. Fernando Figueira. Rua dos Coelhos, 300. Boa Vista. Recife, PE, Brasil. CEP: 50.070-902. 